\title{
Management of hematometrocolpos due to dysfunctional uterine bleeding following progestin use: a case report
}

\author{
Murat Bakacak ${ }^{1}$, Fazil Avci ${ }^{1}$, Mehmet Suhha Bostanci ${ }^{2}$, Zeyneb Bakacak ${ }^{3}$, \\ Salih Serin ${ }^{1}$, Onder Ercan ${ }^{1}$, Bulent Kostu ${ }^{1}$ \\ ${ }^{1}$ Department of Obstetrics and Gynecology, Sutcu Imam University Faculty of Medicine, Kahramanmaras, Turkey; \\ ${ }^{2}$ Department of Obstetrics and Gynecology, Sakarya University Training and Research Hospital, Sakarya, Turkey; \\ ${ }^{3}$ Private Caka Vatan Hospital, Kahramanmaras, Turkey
}

\begin{abstract}
Hematometrocolpos is accumulation of blood in the vagina and uterine cavity due to intra-uterine hemorrhage. A 20-year-old female presented to our clinic with massive menorrhagia at menarche after progestin usage.Hematometrocolpos was detected by transabdominal ultrasonography. She was pale because of heavy bleeding for 5 days and hemoglobin level was measured as $5.1 \mathrm{~g} / \mathrm{dl}$. Initial treatment was blood transfusion and medical drug therapy. After resolution of the hematometrocolpos was shown by transabdominal ultrasound 2 days later, the patient, who was stable, was discharged without complication. Obstruction of the female genital outflow tract is rarely seen. Hematocolpos has been reported in elderly women following vaginal occlusion due to radiotherapy, vaginal fibroma and labial synechiae causing infection or inflammatory conditions. The case is presented here because of the successful management of hematometrocolpos due to massive dysfunctional uterine bleeding in a young virgin patient.
\end{abstract}

Key words: Hematocolpos, pelvic mass, progestin

$\mathrm{H}_{\mathrm{r}}$ eavy menstrual bleeding $(\mathrm{HMB})$ is a general problem with prevalence rates of more than $30 \%$ among adolescents who consult gynaecologists $[1,2,3]$. In a study of 153 girls aged $12-19$ years with bleeding disorders, those who presented with $\mathrm{HMB}$ at menarche and those who required hospitalization were reported at rates of $90 \%$ and $12 \%$, respectively [3]. In addition, it is very important to understand the difference between non- life-threatening bleedings and those requiring emergent intervention [4]. Therefore, a careful anamnesis, and physical examination are essential for diagnosis and management. Uterine bleedings due to obstruction of the lower female genital tract cause proximal dil-

Received: May 26, 2014 Accepted: August 23, 2014 Online: August 03, 2014

Correspondence: Murat BAKACAK. Kahramanmaras Sutcu Imam Universitesi Tip Fakultesi, Kadin Hastalıkları ve Dogum Anabilim Dalı, Kahramanmaras, Turkey.

Tel: +90 344 - 2801000 e-mail: muratbakacak46@gmail.com

(c) Copyright 2014 by Istanbul Northern Anatolian Association of Public Hospitals - Available online at www.kuzeyklinikleri.com 

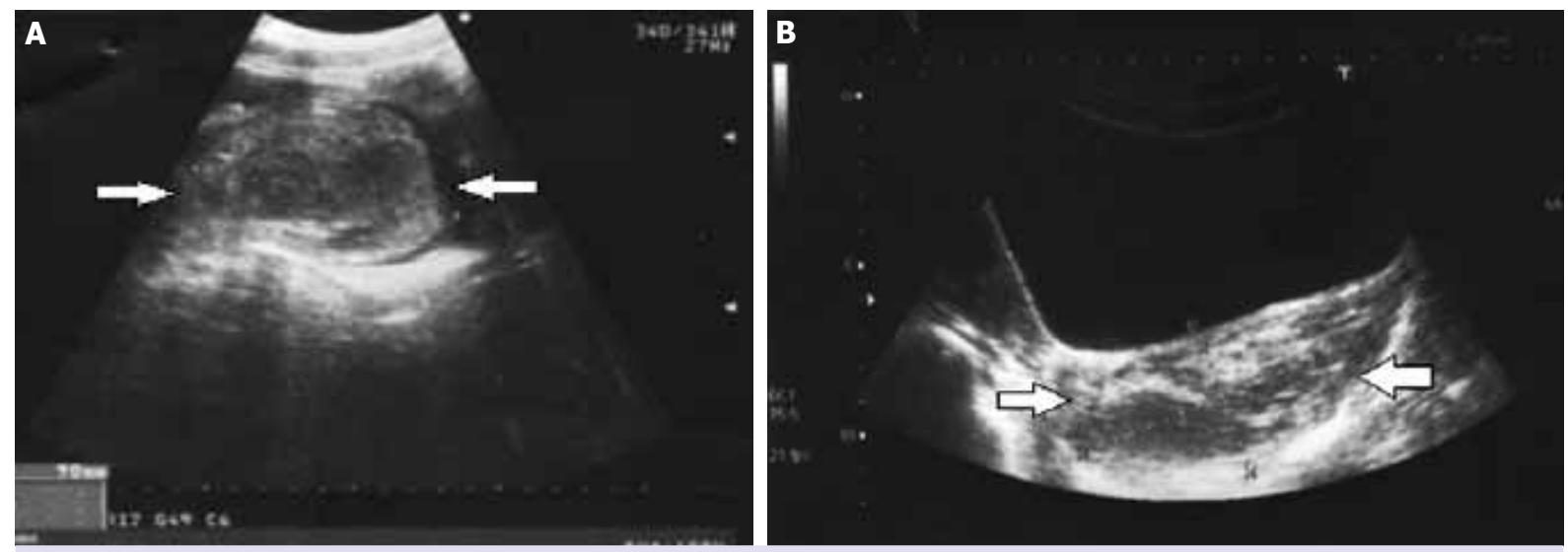

FIGURE 1. (A) Transabdominal sagital ultrasonographic view showing the markedly distended uterus. Heterogeneous structures the largest being $90 \mathrm{~mm}$ in diameter were seen in the uterine cavity. (B) Transabdominal sonographic view showing the markedly distended vagina measuring $88.9 \mathrm{~mm} \times 39.2 \mathrm{~mm}$ (hematocolpos). Heterogeneous structures the largest being $90 \mathrm{~mm}$ in diameter were seen in the vaginal cavity.

atation and the occurrence of hematocolpos, hematotrachelos or hematometra are the most common problems defined as congenital abnormalities $[4,5$, $6]$. Obstruction of the female genital outflow tract is rare $[7,8]$.

The case is presented here because of successful management of hematometrocolpos due to massive dysfunctional uterine bleeding in a young virgin patient.

\section{CASE REPORT}

A 20-year-old virgin patient with an episode of massive menorrhagia at menarche was admitted to the Emergency Room (ER) of the Department of Obstetrics and Gynecology. Her medical history revealed that 15 days prior to the presentation at the Emergency Department, she had been prescribed a ten-day course of progestogen therapy on request to delay her menstrual cycle. She had no known bleeding disorders. Her gynecological history included menarche at 14 years of age. Her periods lasting for 6 to 7 days were normal and regular occurring at 25day intervals. On examination, she was afebrile with blood pressure of $70 / 40 \mathrm{~mm} \mathrm{Hg}$ and pulse rate of 130 beats per minute. Her abdomen was soft, with moderate tenderness of the lower abdomen without rebound. Pelvic examination revealed an intact annular hymen. The hymenal opening was $7-8 \mathrm{~mm}$ in diameter. Coagulated blood bulging outwards from the hymen opening was observed. A large hematometra and hematocolpos were detected by transabdominal ultrasound scanning. Transabdominal ultrasound depicted a distended uterus $90 \mathrm{~mm}$ in diameter (Figure 1a) which communicated with a markedly distended vagina (Figure 1b). Both ovaries were observedly normal. She had been bleeding heavily for 5 days causing a drop in hemoglobin level down to $5.1 \mathrm{gr} / \mathrm{dl}$, while other laboratory test results were unremarkable. Pregnancy test was negative. She was initially treated with blood transfusion (eight units of packed red blood cells and four units of packed fresh-frozen plasma were transfused) and hemostasis was achieved rapidly using high doses of combined oral contaceptive (ethinyl estradiol 0.02 $\mathrm{mg}$, and gestodene $0.075 \mathrm{mg}$ ) twelve times a day, tranexamic acid $1000 \mathrm{mg}$ q.i.d., and naproxen sodium $550 \mathrm{mg}$ b.i.d. After one day, a chocolate-like fluid started to spill out from the vagina. A transabdominal ultrasound obtained 2 days later showed resolution of the hematometrocolpos. The patient was discharged without complication.

\section{DISCUSSION}

Congenital abnormalities resulting in hematometrocolpos include imperforate hymen, a complete transverse vaginal septum, vaginal and, rarely, cervical atresia $[7,8,9]$. Acquired obstruction of the 
lower female genital tract is rare. These acquired problems are caused by iatrogenic interventional traumas to the uterine cervix such as cone biopsies, loop electrosurgical procedures, dilation and curettage, obstetric lacerations, cervical or endometrial carcinoma, and radiation therapy $[9,10,11,12,13$, 14]. Spontaneous obstruction is generally uncommon but has been reported recently [15]. Firstly, pregnancy and pregnancy-related complications need to be excluded from the patient's medical history [1]. About one fifth of females presenting with heavy menstrual periods may have an underlying blood dyscrasia $[2,15,16,17]$. HMB may be associated with a variety of endocrine disorders such as thyroid disease, adrenal problems and other medical problems such as hepatitis, chronic renal disease or diabetes mellitus. In addition, HMB episodes may occur because of disruptions or abnormalities of the coagulation cascade [1].

In the present case, sonographic findings demonstrated acquired obstruction of the lower female genital tract, specifically hematometra and hematocolpos. The intracavitary findings included different degrees of resolving hemorrhage, but a malignancy, although less likely, could not be ruled out. However, presenting symptoms of hematometra and hematocolpos without any evidence of primary and secondary amenorrhea were considered to be related to massive uterine bleeding following the use of progestin fifteen days previously. In the present case, it was thought that massive uterine bleeding could have caused an obstruction secondary to the clot formation. Narrow diameter of the hymenal opening may have facilitated this process. With medical therapy, the patient's clinical symptoms improved, uterine and vaginal bleeding stopped and coagulated blood in the vagina dissolved and drained from the vagina.

As in the present case, abnormal uterine bleeding associated with the use of exogenous steroids, systemic or local agents is classified as "iatrogenic" according to the PALM-COEIN classification system [18].

There are some effective treatment methods for adolescents with HMB. Planning is very important in the treatment of both acute bleed and its maintenance therapy. It is generally recommended that adolescents with active $\mathrm{HMB}$ and hemoglobin of less than $8 \mathrm{mg} / \mathrm{dl}$ should be admitted into ER dur- ing an acute bleed $[5,19]$.

Intravenous crystalloid infusion for the replacement of the blood volume may be given to a patient with an acute HMB episode which is causing anemia [19]. A randomized controlled trial reported that in $72 \%$ of the patients given intravenous $[4,17]$ estrogen, bleeding was stopped after two doses (over $12 \mathrm{~h}$ ) compared with $38 \%$ of controls given a placebo [20]. For adolescents already using combined oral contraceptives (COCs) and admitted with HMB despite treatment, transition to i.v. treatment or higher dose COC are appropriate methods [16]. There is not enough data as yet to recommend one specific type of COC over any other [21].

Antifibrinolytics have the effect of halting the lysis of clots occurring at the end of the clotting cascade thus improving the clotting process. Antifibrinolytics have been reported to decrease bleeding in about half of the women with HMB and can be administered in combination with contraceptive methods [20]. Nonsteroidal anti-inflammatory drugs (NSAIDs) may also decrease HMB. Current studies have also shown that NSAIDs decrease menorrhagia in adolescents compared to placebo (600-1200 mg daily) [22].

Surgical management of adolescents with HMB is seldom necessary as more than $90 \%$ of them will respond to medical management [15].

The underlying etiology of the acquired obstructed cervix in the patient presented here is not as yet fully understood. Potential etiologies include progestin use, decreased uterine contractility triggered by high progestin levels, which might have prevented the effective removal of menstrual debris, and lastly, a possible partial obstruction causing massive uterine bleeding and drainage of bleeding around a solid obstruction. Decreased drainage of accumulated debris rather than acute hemorrhage may have caused hematometrocolpos.

Thus, the underlying etiology of the obstruction in this patient was uncertain, and this case denotes an unusual cause of acquired spontaneous hematometra and hematocolpos developed following progestin use.

\section{Conclusion}

Adolescents often present at gynaecologists with 
$\mathrm{HMB}$, although HMB following the usage of contraceptive pills which may cause hematometrocolpos is rare. The diagnosis and treatment of this situation includes a careful physical, and ultrasonographic examinations, and laboratory tests to exclude other diagnoses such as bleeding disorders, anatomic and endocrine causes. Treatment methods include hormonal therapies, antifibrinolytics and nonsteroidal anti-inflammatory drugs, which are effective, welltolerated and safe. This case shows that a careful history and examination is very important in the recognition of a rarely seen life-threatening menorrhagic episodes arising from usage of progestin with the intention to delay the menstrual cycle.

Informed Consent: Written informed consent was obtained from the patient who participated in this study.

Conflict of Interest: No conflict of interest was declared by the authors.

Financial Disclosure: The authors declared that this study has received no financial support.

\section{REFERENCES}

1. Benjamins LJ. Practice guideline: evaluation and management of abnormal vaginal bleeding in adolescents. J Pediatr Health Care 2009;23:189-93.

2. Jayasinghe Y, Moore P, Donath S, Campbell J, Monagle P, Grover $\mathrm{S}$. Bleeding disorders in teenagers presenting with menorrhagia. Aust N Z J Obstet Gynaecol 2005;45:439-43.

3. Chi C, Pollard D, Tuddenham EG, Kadir RA. Menorrhagia in adolescents with inherited bleeding disorders. J Pediatr Adolesc Gynecol 2010;23:215-22.

4. Tran AT, Arensman RM, Falterman KW. Diagnosis and management of hydrohematometrocolpos syndromes. Am J Dis Child 1987;141:632-4.

5. Ward A, Maher P. Haematocolpos--an unusual presentation. $\mathrm{Br}$ J Clin Pract 1979;33:83-4.

6. Pretorius DH, Dennis MA, Manco-Johnson ML, Gottesfeld KR. Ultrasound diagnosis of hematotrachelos: a case report. Am J Obstet Gynecol 1985;151:1080-2.

7. Sherer DM, Beyth Y. Ultrasonographic diagnosis and assisted surgical management of hematotrachelos and hematometra due to uterine cervical atresia with associated vaginal agenesis. J Ultrasound Med 1989;8:321-3.

8. Sanders RM, Nakajima ST. An unusual late presentation of im- perforate hymen. Obstet Gynecol 1994;83:896-8.

9. Witt BR. Treatment of hematotrachelos after dilatation and curettage. A case report. J Reprod Med 1999;44:68-70.

10. Giannacopoulos K, Troukis E, Constandinou P, Rozis I, Kokonakis C, Giannikos L. Hematometra and extended vaginal haematoma after laser conization. A case report. Eur J Gynaecol Oncol 1998;19:569-70.

11. Scheerer LJ, Bartolucci L. Transvaginal sonography in the evaluation of hematometra. A report of two cases. J Reprod Med 1996;41:205-6.

12. Sherer DM, Khoury-Collado F, Hellmann M, Abdelmalek E, Kheyman M, Abulafia O. Transvaginal sonography of hematotrachelos and hematometra causing acute urinary retention after previous repair of intrapartum cervical lacerations. J Ultrasound Med 2006;25:269-71.

13. Pschera H, Kjaeldgaard A. Haematocervix after conization diagnosed by ultrasonography. Gynecol Obstet Invest 1990;29:309. 10.

14. Sherer DM, Eugene P, Gorelick C, Ramachandran S, Serur E, Kheyman M, et al. Acute spontaneous hematotrachelos following methotrexate treatment of a suspected tubal pregnancy. J Ultrasound Med 2006;25:1091-3.

15. Frishman GN. Evaluation and treatment of menorrhagia in an adolescent population. J Minim Invasive Gynecol 2008;15:6828.

16. James AH. Bleeding disorders in adolescents. Obstet Gynecol Clin North Am 2009;36:153-62.

17. Philipp CS, Faiz A, Dowling N, Dilley A, Michaels LA, Ayers $\mathrm{C}$, et al. Age and the prevalence of bleeding disorders in women with menorrhagia. Obstet Gynecol 2005;105:61-6.

18. Munro MG, Critchley HO, Broder MS, Fraser IS; FIGO Working Group on Menstrual Disorders. FIGO classification system (PALM-COEIN) for causes of abnormal uterine bleeding in nongravid women of reproductive age. Int J Gynaecol Obstet 2011;113:3-13.

19. Wilkinson JP, Kadir RA. Management of abnormal uterine bleeding in adolescents. J Pediatr Adolesc Gynecol 2010;23(6 Suppl):22-30.

20. DeVore GR, Owens O, Kase N. Use of intravenous Premarin in the treatment of dysfunctional uterine bleeding--a double-blind randomized control study. Obstet Gynecol 1982;59:285-91.

21. Ahuja SP, Hertweck SP. Overview of bleeding disorders in adolescent females with menorrhagia. J Pediatr Adolesc Gynecol 2010;23(6 Suppl):15-21.

22. Pinto S, Costa J, Vaz Carneiro A, Fernandes R. Analysis of the Cochrane Review: Antibiotics for acute otitis media in children. Cochrane Database Syst Rev. 2013;1:CD000219. [Article in Portuguese] Acta Med Port 2013;26:633-6. [Abstract] 

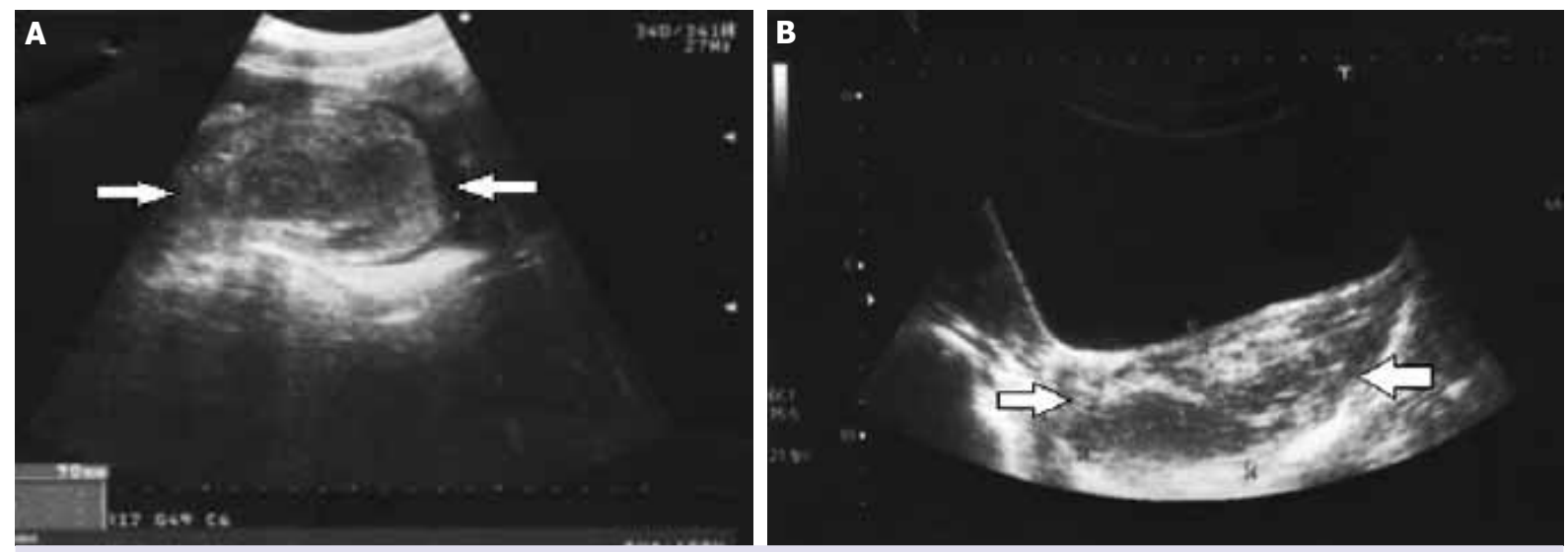

FIGURE 1. (A) Transabdominal sagital ultrasonographic view showing the markedly distended uterus. Heterogeneous structures the largest being $90 \mathrm{~mm}$ in diameter were seen in the uterine cavity. (B) Transabdominal sonographic view showing the markedly distended vagina measuring $88.9 \mathrm{~mm} \times 39.2 \mathrm{~mm}$ (hematocolpos). Heterogeneous structures the largest being $90 \mathrm{~mm}$ in diameter were seen in the vaginal cavity.

atation and the occurrence of hematocolpos, hematotrachelos or hematometra are the most common problems defined as congenital abnormalities $[4,5$, $6]$. Obstruction of the female genital outflow tract is rare $[7,8]$.

The case is presented here because of successful management of hematometrocolpos due to massive dysfunctional uterine bleeding in a young virgin patient.

\section{CASE REPORT}

A 20-year-old virgin patient with an episode of massive menorrhagia at menarche was admitted to the Emergency Room (ER) of the Department of Obstetrics and Gynecology. Her medical history revealed that 15 days prior to the presentation at the Emergency Department, she had been prescribed a ten-day course of progestogen therapy on request to delay her menstrual cycle. She had no known bleeding disorders. Her gynecological history included menarche at 14 years of age. Her periods lasting for 6 to 7 days were normal and regular occurring at 25day intervals. On examination, she was afebrile with blood pressure of $70 / 40 \mathrm{~mm} \mathrm{Hg}$ and pulse rate of 130 beats per minute. Her abdomen was soft, with moderate tenderness of the lower abdomen without rebound. Pelvic examination revealed an intact annular hymen. The hymenal opening was $7-8 \mathrm{~mm}$ in diameter. Coagulated blood bulging outwards from the hymen opening was observed. A large hematometra and hematocolpos were detected by transabdominal ultrasound scanning. Transabdominal ultrasound depicted a distended uterus $90 \mathrm{~mm}$ in diameter (Figure 1a) which communicated with a markedly distended vagina (Figure 1b). Both ovaries were observedly normal. She had been bleeding heavily for 5 days causing a drop in hemoglobin level down to $5.1 \mathrm{gr} / \mathrm{dl}$, while other laboratory test results were unremarkable. Pregnancy test was negative. She was initially treated with blood transfusion (eight units of packed red blood cells and four units of packed fresh-frozen plasma were transfused) and hemostasis was achieved rapidly using high doses of combined oral contaceptive (ethinyl estradiol 0.02 $\mathrm{mg}$, and gestodene $0.075 \mathrm{mg}$ ) twelve times a day, tranexamic acid $1000 \mathrm{mg}$ q.i.d., and naproxen sodium $550 \mathrm{mg}$ b.i.d. After one day, a chocolate-like fluid started to spill out from the vagina. A transabdominal ultrasound obtained 2 days later showed resolution of the hematometrocolpos. The patient was discharged without complication.

\section{DISCUSSION}

Congenital abnormalities resulting in hematometrocolpos include imperforate hymen, a complete transverse vaginal septum, vaginal and, rarely, cervical atresia $[7,8,9]$. Acquired obstruction of the 
lower female genital tract is rare. These acquired problems are caused by iatrogenic interventional traumas to the uterine cervix such as cone biopsies, loop electrosurgical procedures, dilation and curettage, obstetric lacerations, cervical or endometrial carcinoma, and radiation therapy $[9,10,11,12,13$, 14]. Spontaneous obstruction is generally uncommon but has been reported recently [15]. Firstly, pregnancy and pregnancy-related complications need to be excluded from the patient's medical history [1]. About one fifth of females presenting with heavy menstrual periods may have an underlying blood dyscrasia $[2,15,16,17]$. HMB may be associated with a variety of endocrine disorders such as thyroid disease, adrenal problems and other medical problems such as hepatitis, chronic renal disease or diabetes mellitus. In addition, HMB episodes may occur because of disruptions or abnormalities of the coagulation cascade [1].

In the present case, sonographic findings demonstrated acquired obstruction of the lower female genital tract, specifically hematometra and hematocolpos. The intracavitary findings included different degrees of resolving hemorrhage, but a malignancy, although less likely, could not be ruled out. However, presenting symptoms of hematometra and hematocolpos without any evidence of primary and secondary amenorrhea were considered to be related to massive uterine bleeding following the use of progestin fifteen days previously. In the present case, it was thought that massive uterine bleeding could have caused an obstruction secondary to the clot formation. Narrow diameter of the hymenal opening may have facilitated this process. With medical therapy, the patient's clinical symptoms improved, uterine and vaginal bleeding stopped and coagulated blood in the vagina dissolved and drained from the vagina.

As in the present case, abnormal uterine bleeding associated with the use of exogenous steroids, systemic or local agents is classified as "iatrogenic" according to the PALM-COEIN classification system [18].

There are some effective treatment methods for adolescents with HMB. Planning is very important in the treatment of both acute bleed and its maintenance therapy. It is generally recommended that adolescents with active $\mathrm{HMB}$ and hemoglobin of less than $8 \mathrm{mg} / \mathrm{dl}$ should be admitted into ER dur- ing an acute bleed $[5,19]$.

Intravenous crystalloid infusion for the replacement of the blood volume may be given to a patient with an acute HMB episode which is causing anemia [19]. A randomized controlled trial reported that in $72 \%$ of the patients given intravenous $[4,17]$ estrogen, bleeding was stopped after two doses (over $12 \mathrm{~h}$ ) compared with $38 \%$ of controls given a placebo [20]. For adolescents already using combined oral contraceptives (COCs) and admitted with HMB despite treatment, transition to i.v. treatment or higher dose COC are appropriate methods [16]. There is not enough data as yet to recommend one specific type of COC over any other [21].

Antifibrinolytics have the effect of halting the lysis of clots occurring at the end of the clotting cascade thus improving the clotting process. Antifibrinolytics have been reported to decrease bleeding in about half of the women with HMB and can be administered in combination with contraceptive methods [20]. Nonsteroidal anti-inflammatory drugs (NSAIDs) may also decrease HMB. Current studies have also shown that NSAIDs decrease menorrhagia in adolescents compared to placebo (600-1200 mg daily) [22].

Surgical management of adolescents with HMB is seldom necessary as more than $90 \%$ of them will respond to medical management [15].

The underlying etiology of the acquired obstructed cervix in the patient presented here is not as yet fully understood. Potential etiologies include progestin use, decreased uterine contractility triggered by high progestin levels, which might have prevented the effective removal of menstrual debris, and lastly, a possible partial obstruction causing massive uterine bleeding and drainage of bleeding around a solid obstruction. Decreased drainage of accumulated debris rather than acute hemorrhage may have caused hematometrocolpos.

Thus, the underlying etiology of the obstruction in this patient was uncertain, and this case denotes an unusual cause of acquired spontaneous hematometra and hematocolpos developed following progestin use.

\section{Conclusion}

Adolescents often present at gynaecologists with 
$\mathrm{HMB}$, although HMB following the usage of contraceptive pills which may cause hematometrocolpos is rare. The diagnosis and treatment of this situation includes a careful physical, and ultrasonographic examinations, and laboratory tests to exclude other diagnoses such as bleeding disorders, anatomic and endocrine causes. Treatment methods include hormonal therapies, antifibrinolytics and nonsteroidal anti-inflammatory drugs, which are effective, welltolerated and safe. This case shows that a careful history and examination is very important in the recognition of a rarely seen life-threatening menorrhagic episodes arising from usage of progestin with the intention to delay the menstrual cycle.

Informed Consent: Written informed consent was obtained from the patient who participated in this study.

Conflict of Interest: No conflict of interest was declared by the authors.

Financial Disclosure: The authors declared that this study has received no financial support.

\section{REFERENCES}

1. Benjamins LJ. Practice guideline: evaluation and management of abnormal vaginal bleeding in adolescents. J Pediatr Health Care 2009;23:189-93. CrossRef

2. Jayasinghe Y, Moore P, Donath S, Campbell J, Monagle P, Grover $\mathrm{S}$. Bleeding disorders in teenagers presenting with menorrhagia. Aust N Z J Obstet Gynaecol 2005;45:439-43. CrossRef

3. Chi C, Pollard D, Tuddenham EG, Kadir RA. Menorrhagia in adolescents with inherited bleeding disorders. J Pediatr Adolesc Gynecol 2010;23:215-22. CrossRef

4. Tran AT, Arensman RM, Falterman KW. Diagnosis and management of hydrohematometrocolpos syndromes. Am J Dis Child 1987;141:632-4.

5. Ward A, Maher P. Haematocolpos--an unusual presentation. $\mathrm{Br}$ J Clin Pract 1979;33:83-4.

6. Pretorius DH, Dennis MA, Manco-Johnson ML, Gottesfeld KR. Ultrasound diagnosis of hematotrachelos: a case report. Am J Obstet Gynecol 1985;151:1080-2. CrossRef

7. Sherer DM, Beyth Y. Ultrasonographic diagnosis and assisted surgical management of hematotrachelos and hematometra due to uterine cervical atresia with associated vaginal agenesis. J Ultrasound Med 1989;8:321-3.

8. Sanders RM, Nakajima ST. An unusual late presentation of im- perforate hymen. Obstet Gynecol 1994;83:896-8.

9. Witt BR. Treatment of hematotrachelos after dilatation and $\mathrm{cu}-$ rettage. A case report. J Reprod Med 1999;44:68-70.

10. Giannacopoulos K, Troukis E, Constandinou P, Rozis I, Kokonakis C, Giannikos L. Hematometra and extended vaginal haematoma after laser conization. A case report. Eur J Gynaecol Oncol 1998;19:569-70.

11. Scheerer LJ, Bartolucci L. Transvaginal sonography in the evaluation of hematometra. A report of two cases. J Reprod Med 1996;41:205-6.

12. Sherer DM, Khoury-Collado F, Hellmann M, Abdelmalek E, Kheyman M, Abulafia O. Transvaginal sonography of hematotrachelos and hematometra causing acute urinary retention after previous repair of intrapartum cervical lacerations. J Ultrasound Med 2006;25:269-71.

13. Pschera H, Kjaeldgaard A. Haematocervix after conization diagnosed by ultrasonography. Gynecol Obstet Invest 1990;29:309. 10. CrossRef

14. Sherer DM, Eugene P, Gorelick C, Ramachandran S, Serur E, Kheyman $\mathrm{M}$, et al. Acute spontaneous hematotrachelos following methotrexate treatment of a suspected tubal pregnancy. J Ultrasound Med 2006;25:1091-3.

15. Frishman GN. Evaluation and treatment of menorrhagia in an adolescent population. J Minim Invasive Gynecol 2008;15:6828. CrossRef

16. James AH. Bleeding disorders in adolescents. Obstet Gynecol Clin North Am 2009;36:153-62. CrossRef

17. Philipp CS, Faiz A, Dowling N, Dilley A, Michaels LA, Ayers $\mathrm{C}$, et al. Age and the prevalence of bleeding disorders in women with menorrhagia. Obstet Gynecol 2005;105:61-6. CrossRef

18. Munro MG, Critchley HO, Broder MS, Fraser IS; FIGO Working Group on Menstrual Disorders. FIGO classification system (PALM-COEIN) for causes of abnormal uterine bleeding in nongravid women of reproductive age. Int J Gynaecol Obstet 2011;113:3-13. CrossRef

19. Wilkinson JP, Kadir RA. Management of abnormal uterine bleeding in adolescents. J Pediatr Adolesc Gynecol 2010;23(6 Suppl):22-30. CrossRef

20. DeVore GR, Owens O, Kase N. Use of intravenous Premarin in the treatment of dysfunctional uterine bleeding--a double-blind randomized control study. Obstet Gynecol 1982;59:285-91.

21. Ahuja SP, Hertweck SP. Overview of bleeding disorders in adolescent females with menorrhagia. J Pediatr Adolesc Gynecol 2010;23(6 Suppl):15-21. CrossRef

22. Pinto S, Costa J, Vaz Carneiro A, Fernandes R. Analysis of the Cochrane Review: Antibiotics for acute otitis media in children. Cochrane Database Syst Rev. 2013;1:CD000219. [Article in Portuguese] Acta Med Port 2013;26:633-6. [Abstract] 